\title{
BASES LEGAIS E TÉCNICAS PARA A ADEQUAÇÃO AMBIENTAL DE PEQUENAS PROPRIEDADES RURAIS: $O$ CASO DO BAIRRO CHAPARRAL, MUNICÍPIO DE BOTUCATU/SP.
}

\author{
Loreanna Bertolucci de Araujo Anastácio \\ Luiz César Ribas ${ }^{2}$ \\ Stella Vannucci Lemos ${ }^{3}$
}

\begin{abstract}
RESUMO
A preocupação com a questão ambiental de um modo geral e, de forma mais específica, com os recursos florestais, tem adquirido uma dimensão tanto nacional quanto internacional cada vez maior. No âmbito nacional, a partir da criação de diversos dispositivos normativos que promovem a inovação de diversos preceitos técnicos e legais que buscam conciliar, desde a edição da Lei n. 12,651, no ano de 2012, até mais recentemente, com a edição do Decreto n. 8.375, de 11 de dezembro de 2014, tanto a proteção florestal quanto a produção florestal madeireira e não madeireira. No âmbito internacional, o exemplo mais recente é a promulgação da Declaração de Nova York sobre as Florestas. $O$ presente trabalho, tendo como pano de fundo justamente este cenário nacional e internacional, busca a proposição de diretrizes principais visando à adequação ambiental particularmente do universo das pequenas propriedades rurais na região do município de Botucatu/SP e, com isto, propiciar tanto a proteção ambiental quanto o uso sustentável dos recursos florestais. Para tanto, vale-se do conjunto de propriedades rurais de agricultores familiares do Bairro Chaparral como estudo de caso. Com base num conjunto normativo referencial, no qual, foram formuladas as principais diretrizes técnicas e legais que podem nortear, considerando as especificidades da sustentabilidade social, econômica e ambiental locais, o processo de adequação ambiental de pequenas propriedades rurais da região do presente estudo. Concluiu-se que os principais aspectos de adequação ambiental de pequenas propriedades rurais e posses rurais familiares preconizados pela nova lei florestal, são plenamente compatíveis com a proteção e o uso sustentável dos recursos florestais.
\end{abstract}

PALAVRAS-CHAVE: Carta de Nova York, Código Florestal, Agricultura Familiar.

\footnotetext{
${ }^{1}$ Acadêmica do curso de Engenharia Agronômica, Faculdade de Ciências Agronômicas (FCA). Universidade Estadual Paulista "Julio de Mesquita Filho" (UNESP, Campus Fazenda Lageado, Botucatu/SP, Email:Ibdaanastacio@fca.unesp.br

${ }_{2}^{2}$ Professor Universitário. Engenheiro Florestal. Departamento de Economia, Sociologia e Tecnologia. Faculdade de Ciências Agronômicas (FCA). Universidade Estadual Paulista "Júlio de Mesquita Filho" (UNESP). Campus da Fazenda Lageado, Botucatu/SP. E-mail: Icribas@fca.unesp.br

${ }^{3}$ Engenheira Agrônoma. Mestre em Agronomia: Energia na Agricultura, Faculdade de Ciências Agronômicas (FCA). Universidade Estadual Paulista "Júlio de Mesquita Filho" (UNESP, Campus Fazenda Lageado, Botucatu/SP). Email: sylemos@yahoo.com.br.
} 


\title{
LEGAL BASIS AND TECHNIQUES FOR ENVIRONMENTAL FITNESS FOR SMALL RURAL PROPERTIES: THE NEIGHBORHOOD CASE CHAPARRAL, MUNICIPALITY OF BOTUCATU / SP.
}

\begin{abstract}
The concern with environmental issues in general and, more specifically, with forest resources, has acquired specific and international dimension increasing. At the national level, through the creation of various regulatory provisions that promote innovation of various technical and legal provisions that seek to reconcile, since the enactment of Law $n$. 12.651, in 2012, to more recently with the publication of Decree n. 8.375, of December 11, 2014, both forest protection and timber and non-timber forest production. Internationally, the most recent example is the promulgation of the New York Declaration on Forests. This work, with the backdrop of precisely this national and international scene, search the proposition main guidelines aimed at environmental compliance particularly the universe of small farms in the region of Botucatu / SP and, thus, provide both protection environmental and sustainable use of forest resources. Therefore, it is the number of farms of farmers Chaparral District as a case study. Based on a reference set of rules in which the main legal and technical guidelines were formulated that can guide considering the specificities of social, economic and environmental areas, the environmental compliance process of small farms of this study area. It was concluded that the main aspects of environmental adaptation of small family farms and rural possessions recommended by the new forestry law, are fully compatible with the protection and sustainable use of forest resources.
\end{abstract}

KEYWORDS: Letter of New York, Forest Law, Family Agriculture.

\section{FUNDAMENTOS Y TÉCNICAS PARA LA ADECUACIÓN AMBIENTAL PARA PEQUEÑOS RURAL PROPIEDADES LEGAL: EL BARRIO CHAPARRAL CASO, MUNICIPIO DE BOTUCATU / SP.}

\begin{abstract}
RESUMEN
La preocupación por los temas ambientales en general y, más concretamente, con los recursos forestales, ha adquirido tanto la dimensión nacional e internacional cada vez mayor. A nivel nacional, a través de la creación de diversas disposiciones reglamentarias que promuevan la innovación de diversas disposiciones técnicas y legales que tratan de conciliar, desde la promulgación de la Ley $\mathrm{n}$. 12.651, en 2012, a más recientemente con la publicación del Decreto n. 8.375, de 11 de diciembre de 2014, tanto la protección forestal y de la madera y de la producción forestal no maderable. A nivel internacional, el ejemplo más reciente es la promulgación de la Declaración de Nueva York sobre los Bosques. Esta obra, con el telón de fondo de precisamente esta escena nacional e internacional, buscar las principales directrices de proposición dirigidas a cumplimiento ambiental particular universo de pequeñas granjas en la región de Botucatu / SP y, por lo tanto, proporcionar tanto protección uso ambiental y sostenible de los recursos forestales. Por lo tanto, es el número de explotaciones de los agricultores Chaparral Distrito como caso de estudio. Sobre la base de un conjunto de referencia de las normas en las que se formularon los principales lineamientos legales y técnicas que puede guiar considerando las especificidades de las áreas sociales, económicas y ambientales, el proceso de cumplimiento ambiental de las pequeñas explotaciones de esta área de estudio. Se concluyó que los principales aspectos de la adaptación ambiental de las pequeñas explotaciones familiares y posesiones rurales recomendadas por la nueva ley forestal, son totalmente compatibles con la protección y el uso sostenible de los recursos forestales.
\end{abstract}

PALABRAS CLAVE: Carta de Nueva York, la Ley Forestal, Agricultura Familiar. 


\section{INTRODUÇÃO}

A mais recente demonstração da preocupação e da importância ambiental com os recursos florestais pode ser observada no documento Declaração de Nova York sobre as Florestas. Este documento trata-se de uma iniciativa voluntária com o objetivo de orientar os esforços de governos ${ }^{4}$, companhias ${ }^{5}$ e instituições da sociedade civil $^{6}$ com respeito às novas políticas de conservação e restauração florestal e encontra-se inserido dentro do espírito da Agenda 21 (ONU, 2014).

O Brasil não é um dos signatários do referido documento ambiental e as autoridades justificam isto com base nos seguintes argumentos: i) a declaração de Nova York sobre as Florestas não é um acordo; ii) a declaração foi assinada por apenas 28 dos 130 países participantes da Cúpula do Clima 2014 da ONU; iii) o Brasil tem a maior reserva florestal do mundo e não foi chamado à elaboração da proposta; iv) outros países detentores de grandes florestas também foram ignorados e não assinaram depois do documento pronto; v) o Brasil tentou fazer colaborações, mas não teve sua sugestões acatadas; vi) assinar a declaração significaria atestar como verdadeira a doação de US\$ 5 bilhões a países que promovem ações contra o desmatamento, sendo que o valor real é de US $\$ 2,3$ bilhões; vii) a declaração ignora as responsabilidades sobre a preservação ambiental assumida pelos países desenvolvidos e abre a possibilidade de transferir estes encargos ao setor privado, e viii) a declaração fere o Código Florestal, aprovado democraticamente pela sociedade brasileira (PORTAL BRASIL, 2014).

\section{É exatamente dentro do contexto do panorama florestal brasileiro} relativamente à Carta de Nova York sobre as florestas, naturalmente que deixandose o escopo dos fundos monetários internacionais de lado e focando-se, primordialmente, os aspectos técnicos e legais, que poderia ser introduzida a nova

\footnotetext{
${ }^{4}$ Dos 27 países signatários, 9 são desenvolvidos (Bélgica, França, Alemanha, Japão, Holanda, Noruega, Coréia do Sul, Reino Unido e Estados Unidos da América), 13 latino americanos, do leste europeu ou asiáticos (Chile, Colômbia, Costa Rica, Guiana, Indonésia, Libéria, Lituânia, México, Mongólia, Nepal, Peru, Filipinas e Vietnã) e 5 africanos (Costa do Marfim, Congo, Etiópia, Quênia e Togo).

${ }^{5} \mathrm{Um}$ total de 24 companhias multinacionais, dentre as quais, Cia de Papel e Celulose da Ásia, Cargill, Danone, McDonalds, Nestlé e Wallmart.

645 Instituições Não Governamentais, tais como, World Resources Institute, WWF, The Nature Conservancy, Sustainable Development Policy Institute (SDPI) e The Energy and Resources Institute (TERI).
} 
lei florestal brasileira, também, denominada Lei n. 12.651, de 25 de maio de 2012 (BRASIL, 2012).

Este importante e recente instrumento de política pública para a proteção da vegetação nativa do território nacional incorpora (na verdade, sistematiza) uma série de importantes parâmetros, sobretudo sob o prisma da sustentabilidade social, econômica e ambiental, que vieram sendo incorporados à proteção, conservação e preservação dos recursos florestais ao longo do tempo como, por exemplo, pequenas propriedades e posses rurais familiares ${ }^{7}$.

Para tanto, a nova lei florestal preconiza uma conjunto de requisitos técnicos e legais que devem ser atendidos pelas propriedades rurais, e dentro do presente contexto em específico, das pequenas propriedades e posses rurais familiares, do território nacional visando à adequação ambiental aos ditames de proteção e uso sustentável dos recursos florestais (BRASIL, 2014).

\subsection{OBJETIVOS}

O objetivo do presente trabalho é o analisar, a partir de um estudo de caso e tendo como pano de fundo a Carta de Nova York das Florestas, as principais diretrizes técnicas e legais a serem contempladas para a adequação ambiental das pequenas propriedades e posses rurais familiares conforme preconizadas, pela nova lei florestal, visando a proteção e o uso sustentável dos recursos florestais.

A principal hipótese é a de que é possível promover, apoiando-se nos mecanismos de proteção e uso sustentável dos recursos florestais previstos na nova lei florestal, a adequação ambiental de pequenas propriedades rurais e posses rurais familiares, de forma compatível com as principais diretrizes preconizadas pela Carta de Nova York de Florestas.

\subsection{METODOLOGIA}

O método dedutivo aqui empregado é composto das etapas: i) seleção, sistematização e análise de bibliografia impressa e eletrônica pertinente ao tema, e;

\footnotetext{
${ }^{7}$ A primeira significativa menção a este aspecto específico do escopo social da sustentabilidade dos recursos florestais foi introduzida no ano de 2001 (BRASIL, 2001).
} 
ii) elaboração das conclusões levantadas por intermédio da análise realizada para, com isto, oferecer um diagnóstico para a adequação ambiental de pequenas propriedades rurais e posses rurais familiares. Partindo-se de premissas gerais dos dispositivos técnicos, normativos (voluntários) e legais (mandatórios) pertinentes e com base em uma cadeia de raciocínio, em ordem decrescente de análise, do geral para o específico, efetuou-se a comparação, compreensão e análise das relações entre os principais elementos desta pesquisa, tais como, pequenas propriedades ou posses rurais familiares, áreas rurais consolidadas, áreas de preservação permanente, áreas de Reserva Legal, dentre outros previstos na nova lei florestal em termos de adequação ambiental, para fins da proteção e manejo sustentável dos recursos florestais (SILVA; MENEZES, 2005).

Para tanto, foi desenvolvido um estudo de caso, a partir da análise do conjunto de pequenas propriedades rurais localizadas no Bairro Chaparral, oriundo do desmembramento da antiga Fazenda do Chaparral, localizado no bairro de Rubião Jr, no município de Botucatu, Estado de São Paulo, Brasil.

Pesquisas do tipo Estudo de Caso, com natureza descritiva e orientação epistemológica qualitativa, são apropriadas para a situação na qual se pretende explicar a situação a partir da prática (GODOY, 2006).

Eisenhardt (1989) complementa ao afirmar que o Estudo de Caso proporciona uma fonte de exploração de situações particulares ou específicas, onde os estudos podem gerar resultados e conclusões especialmente reveladores.

A abordagem utilizada, segundo disposto em Silva e Menezes (2005), foi a do tipo "exploratória", "descritiva" e "explicativa", uma vez que houve o uso da pesquisa bibliográfica e documental e análise de experiências relativas ao tema aqui pesquisado, bem como, a descrição e identificação das relações das principais variáveis associadas ao presente trabalho.

\subsection{RESULTADOS}

De início, haveria que se estabelecer o cenário histórico-evolutivo relacionado às principais bases técnicas e legais da nova lei florestal conforme a proposta do presente trabalho. 
Posteriormente, haveria que se apresentar as principais características da Declaração de Nova York sobre as Florestas que poderiam ser destacadas para fins da análise do panorama técnico e legal da proteção ambiental e do uso sustentável dos recursos florestais no país.

Finalmente, os principais aspectos técnicos e legais decorrentes tanto da questão ambiental-florestal nacional quanto internacional haveriam que ser analisadas com respeito ao presente estudo de caso e, com isto, desenhar-se uma proposta de adequação ambiental que propiciasse a proteção e o uso sustentável dos recursos florestais de pequenas propriedades rurais da região objeto do presente estudo de caso.

\subsection{BASES TÉCNICAS E LEGAIS}

No ano de 2012 foi editado o "novo Código Florestal" com a proposta de proporcionar segurança jurídica (e técnica) para a geração de oportunidades (geração de bens e serviços, riqueza, distribuição de renda, qualidade de vida, emprego, desenvolvimento sustentável) para os produtores rurais (BRASIL, 2012).

Esta nova lei florestal em 2012 deve ser analisada dentro da perspectiva de todo um quadro histórico-evolutivo de uma política voltada para a proteção ambiental e produção florestal iniciada nos idos de 1965, quando do advento da Lei n. 4.771, de 15 de setembro de 1965, que introduziu no país importantes elementos voltados para a normatização do uso dos recursos florestais brasileiros, tais como: Incentivos Fiscais para Reflorestamento (pessoas físicas e jurídicas); Processo de Substituição de Importações (Desenvolvimento econômico, Ordem Mundial); estímulo ao desenvolvimento industrial dos setores de Papel e Celulose e de Carvão Vegetal, fomento do reflorestamento homogêneo de espécies exóticas (Pinus spp e Eucalyptus spp), garantia da disponibilidade de matéria-prima florestal, dentre outros aspectos de segurança técnica e jurídica.

De 1965 para cá, todavia, a lei florestal passou por uma série de modificações que proporcionaram um direcionamento mais efetivo dos recursos florestais para objetivos de proteção ambiental.

Com a extinção dos Incentivos Fiscais para Reflorestamento em 1988, bem como com o advento de importantes dispositivos legais constitucionais e 
infraconstitucionais, além de eventos nacionais e internacionais (Política Nacional do Meio Ambiente, Lei da Ação Civil Pública, Resolução CONAMA n. 001/86, Constituição Federal de 1988, Eco-92, dentre outros), a questão da sustentabilidade (social, econômica e ambiental) dos recursos florestais tornou-se bastante incisiva no país e, para tanto, o Código Florestal teve uma participação bastante expressiva.

Entre a edição da nova lei florestal, a Lei n. 12.651, de 25 de maio de 2012 e a última expressiva modificação do então em vigência Código Florestal (qual seja, a MP n. 2.166-67, de 2001), decorreram 11 anos.

Atualmente, a perspectiva técnica, econômica, administrativa, legal e, porque não, criminal, da nova lei florestal encontra-se estabelecida, tendo-se como principal referência o Estado de São Paulo, dentro do contexto do seguinte corpo normativo: (i) Medida Provisória n. 571, de 25 de maio de 2012; (ii) Lei n. 12.727, de 17 de outubro de 2012; (iii) Decreto n. 7.830, de 17 de outubro de 2012. Sistema de Cadastro Ambiental Rural, Cadastro Ambiental Rural e Programas de Regularização Ambiental; (iv) Decreto n. 8.235, de 05 de maio de 2014. Normas gerais complementares aos Programas de Regularização Ambiental dos Estados e do Distrito Federal e Programa Mais Ambiente Brasil; (v) Programa Mais Ambiente Brasil: Ações de apoio à regularização ambiental: Educação Ambiental; AT e ER; Sementes e Mudas, e; Capacitação pública; (vi) Instrução Normativa n. 2, de 5 de maio de 2014 - Integração, execução e compatibilização do Sistema de Cadastro Ambiental Rural-SICAR e procedimentos gerais do Cadastro Ambiental Rural-CAR, e (vii) Resolução SMA n. 32 de 30 de abril de 2014 - Restauração ecológica no Estado de São Paulo (RIBAS, 2014).

Não se pode descuidar, de outra forma, da seguinte base florestal jurídicocriminal em trânsito: (i) Lei n. 9.605, de 12 de fevereiro de 1998 e Decreto n. 6.514, de 22 de julho de 2008; (ii) Ações Diretas de Inconstitucionalidade (Ação Direta de Inconstitucionalidade n. 4901; Ação Direta de Inconstitucionalidade n. 4902; Ação Direta de Inconstitucionalidade n. 4.903, e; Declaração pela $2^{\mathrm{a}}$ Vara da Justiça Federal e Uberaba da Inconstitucionalidade do artigo 62 do Novo Código Florestal).

A partir disto, um dos principais e primeiros aspectos a serem considerados para o atendimento do quadro de conformidade ambiental apresentado pela nova lei florestal refere-se à "dobradinha" Cadastro Ambiental Rural (CAR) e ao Programa de 
Regularização Ambiental (PRA) tal como estabelecidos no Decreto n. 7.830, de 17 de outubro de 2012.

Isto porque, a Lei n. 12.651/2012 dispõe, textual e taxativamente que, com respeito ao Cadastro Ambiental Rural, "a inscrição no CAR será obrigatória para todas as propriedades e posses rurais, devendo ser requerida no prazo de 1 (um) ano contado da sua implantação, prorrogável, uma única vez, por igual período por ato do Chefe do Poder Executivo".

Com o estímulo ao desenvolvimento de um modelo econômico de desenvolvimento sustentável e a questão do CAR e do PRA remete as propriedades rurais, aqui se referindo, particularmente, ao contexto do Estado de São Paulo, a importantes variáveis a serem consideradas, tais como, custos de restauração florestal, para sua execução, modelos de sistemas agroflorestais, boas práticas agrícolas e florestais (viveiro de mudas, sombreamento de pastagens, irrigação, drenagem, adubação, criação, organização e mobilização em associativismo e cooperativismo, gestão da propriedade agrícola, dentre outros).

Até porque, os proprietários rurais tendem a considerar as Matas Ciliares (tipologia de área de preservação permanente) e as áreas de Reserva Legal como passivos ambientais de elevado custo, não reconhecendo os serviços ambientais prestados pelas mesmas ou a potencial geração de renda através do mercado de carbono e do uso sustentável dos recursos florestais permitido pela Lei, por exemplo.

Também não haveria que se esquecer do disposto no art. 72, da Lei $\mathrm{n}$. 12.651/2012, que dispõe, textualmente, que "para efeitos desta Lei, a atividade de silvicultura, quando realizada em área apta ao uso alternativo do solo, é equiparada à atividade agrícola, nos termos da Lei no 8.171 , de 17 de janeiro de 1991, que dispõe sobre a política agrícola" (BRASIL, 1991; BRASIL, 2012).

Isto porque dentro justamente deste contexto é que foi editado o Decreto $\mathrm{n}$. 8.375, de 11 de dezembro de 2014, que definiu a Política Agrícola para Florestas Plantadas.

Dentro deste escopo, as unidades rurais familiares do Bairro Chaparral, que foi objeto de recente evidência por conta de projetos e parcerias institucionais que enfatizam trabalhos associativos dos pequenos produtores rurais locais vinculados à agricultura orgânica, alimentação saudável, segurança alimentar, agricultura familiar, 
merenda escolar, dentre outros, apresenta-se como uma localidade de acentuado potencial de estudo, análise e apoio ao enquadramento dentro de uma situação de conformidade ambiental especialmente no que diz respeito, em termos de adequação ambiental, ao CAR e ao PRA.

O projeto de adequação ambiental, contemplando uma perspectiva de geração de renda minimamente satisfatória, deve buscar a redução do quadro de agressão antrópica ao meio ambiente, praticando-se de um manejo conservacionista dos solos agrícolas, efetuando-se um planejamento agrícola em conformidade com a legislação ambiental, propiciando a conservação dos recursos naturais (sobretudos os hídricos e os florestais), além da gestão ambiental dos resíduos agrícolas. A adequação ambiental local deve também passar pela recuperação de fragmentos florestais, áreas de APP e de Reserva Legal, além da restauração ambiental para a conservação da biodiversidade e recursos hídricos, contemplando também a geração de benefícios econômicos e sociais para as comunidades envolvidas.

\subsection{DECLARAÇÃO DE NOVA YORK SOBRE FLORESTAS}

A Declaração de Nova York sobre as Florestas pretende apontar novas políticas para a conservação e restauração florestal ao redor do mundo, com destaque especial para novos programas multilaterais e bilaterais de remuneração dos países para a redução dos desmatamentos nos próximos seis anos (ONU, 2014).

Segundo este documento, entidades representativas de diversas etnias indígenas também se fizeram representar e, apesar do governo brasileiro não ter sido representando, o Governo do Estado do Acre e o Instituto de Pesquisa Ambiental da Amazônia figuram entre os signatários do referido documento ambiental.

A despeito disto, o documento, dentro de uma perspectiva ampla, tece diversas considerações que se referem ao Brasil enquanto um dos principais global players na conservação e recuperação das florestas ao mencionar os grandes avanços do país em termos da redução das taxas de desmatamento (emissão evitada de carbono e mitigação dos efeitos das mudanças climáticas). 


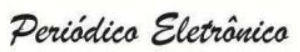

A Declaração das Florestas, ainda com respeito ao Brasil, ressalta que o país, dentro de uma relação de 75 nações, está implantando, dentro do contexto das contribuições climáticas, bem como das Metas de Aichi de Biodiversidade, gerenciadas pelas Nações Unidas, estratégicas nacionais e planos de ação, para não somente reduzir a perda de cobertura florestal como, também, aumentar a área florestal bem como o manejo sustentável de seus recursos florestais (ONU, 2014).

Neste ponto, interessante seria destacar-se das Metas de Aichi, para os objetivos que se pretende no presente trabalho, a Meta 3: "Até 2020, no mais tardar, incentivos, inclusive subsídios, lesivos à biodiversidade terão sido eliminados ou reformados, ou estarão em vias de eliminação visando minimizar ou evitar impactos negativos, e incentivos positivos para a conservacão e uso sustentável de biodiversidade terão sido elaborados e aplicados, consistentes e em conformidade com a Convenção e outras obrigações internacionais relevantes, levando em conta condições socioeconômicas nacionais" (MMA, 2014).

O documento voluntário da $\mathrm{ONU}$, por outro lado, imputa especial ênfase às pesquisas e às ações jurídicas da sociedade civil organizada, de forma a incrementar o entendimento científico e construir elementos de suporte público para políticas de recuperação e conservação das florestas, além de estimular as ações das empresas de uma maneira em geral. De semelhante relevância no documento encontra-se a menção à participação incisiva das comunidades locais em países florestais de forma a fortalecer os aspectos de manejo dos recursos, transparência, contabilidade e leis que devem pautar as novas políticas púbicas de conservação florestal e de proteção ambiental (ONU, 2014).

No que se refere, particularmente, às ações dos governos, ONU (2014) enfatiza os seguintes aspectos: i) esforços para alcançar as Metas Aichi de Biodiversidade até o ano de 2010; ii) necessidade de se alinhar os incentivos fiscais e econômicos para a conservação e recuperação florestal; iii) políticas institucionais para proteger e proporcionar o manejo florestal sustentável dos recursos florestais, bem como estimular a expansão da agricultura para áreas não florestadas e terras degradadas, sem descuidar do desenvolvimento sustentável e equitativo; iv) apoio aos pequenos produtores em termos de práticas de manejo em conformidade com políticas e incremento de produtividade tanto em áreas existentes quanto em novas áreas não florestadas; v) oportunidades para novas alternativas econômicas às 
perdas florestais, e; vi) apoiar países parceiros por intermédio de incentivos econômicos e assistência técnica.

\subsection{BAIRRO CHAPARRAL}

O estudo do loteamento rural Jardim Chaparral, sob o ponto de vista da adequação ambiental de suas propriedades rurais, deve passar necessariamente pela consideração de diversos preceitos técnicos e legais tais como dispostos na Lei n. 12.651/2012, que instituiu a nova lei florestal (BRASIL, 2012).

Neste sentido, a realidade social, econômica e ambiental das propriedades rurais localizadas no Jardim Chaparral devem se enquadrar, nas normas gerais sobre a proteção da vegetação, áreas de Preservação Permanente e as áreas de Reserva Legal, bem como sobre a exploração florestal, o suprimento de matériaprima florestal, o controle da origem dos produtos florestais e o controle e prevenção dos incêndios florestais e, por fim, devem se posicionar sobre o eventual uso de instrumentos econômicos e financeiros preconizados na Lei n. 12.651/2012 (BRASIL, 2012).

As propriedades rurais do Jardim Chaparral devem ser administradas ademais, com vistas ao desenvolvimento sustentável do meio rural, de maneira a contribuir, inclusive dentro do escopo do abastecimento dos mercados de alimentos e bioenergia, para a reafirmação da importância da função estratégica da atividade agropecuária e do papel das florestas e demais formas de vegetação nativa na sustentabilidade, no crescimento econômico, na melhoria da qualidade de vida da população em geral, brasileira .

Para fins da análise da adequação ambiental das propriedades rurais do Jardim Chaparral consoante até aqui disposto e, considerando a classificação das mesmas na condição de "pequena propriedade ou posse rural familiar"

Para efeitos de enquadramento neste caso, contudo, nas propriedades rurais do Jardim Chaparral deveriam ser atendidos, conforme se pode depreender de BRASIL (2014), bem como de BRASIL (2012), os seguintes requisitos legais:

- $\quad$ O agricultor familiar e/ou empreendedor familiar rural que pratica atividades no meio rural local não pode deter, a qualquer título, área maior do que 4 (quatro) módulos fiscais; 
- Deve utilizar predominantemente mão-de-obra da própria família nas atividades econômicas do seu estabelecimento ou empreendimento;

- Deve ter percentual mínimo da renda familiar originada de atividades econômicas do seu estabelecimento ou empreendimento, na forma definida pelo Poder Executivo;

- Deve dirigir seu estabelecimento ou empreendimento com sua família.

Ademais, o enquadramento das propriedades rurais localizadas no Jardim Chaparral na condição de "pequenas propriedades ou posses rurais familiares" deve considerar que haja o desenvolvimento de atividades agrossilvipastoris.

Contudo, apenas isto não basta, pois, segundo os ditames da nova lei florestal, as propriedades rurais do Jardim Chaparral, dado o histórico antigo de uso e ocupação antrópica da área, deveriam ser analisadas sob a ótica da "área rural consolidada", a qual nada mais seria do que a "área de imóvel rural com ocupação antrópica preexistente a 22 de julho de 2008, com edificações, benfeitorias ou atividades agrossilvipastoris, admitida, neste último caso, a adoção do regime de pousio".

Isto porque, a pura e simples tipificação das propriedades rurais localizadas no Jardim Chaparral tanto na condição de "pequenas propriedades ou posses rurais familiares" quanto na situação de "área rural consolidada", já proporcionaria, nos termos da nova lei florestal, todo um rol de especificações, detalhamentos e condicionamentos quanto ao uso e ocupação antrópica das áreas, bem como ao uso e proteção dos recursos florestais (e demais recursos naturais), o qual será justamente objeto do presente projeto de pesquisa.

Assim, considerando as duas condições anteriormente mencionadas, as propriedades rurais do Jardim Chaparral deverão ser analisadas, em termos dos seus respectivos processos de adequação ambiental, com respeito aos seguintes tópicos:

- Atividades de Utilidade Pública (alínea "d", Inc. VIII, art. 3o, Lei n. 12.651/2012);

- $\quad$ Atividades de Interesse Social (alíneas "a" 'b", "c", "d", "e", "f" e "g", Inc. IX, art. 3ํㅡ, Lei n. 12.651/2012); 
- Atividades de Baixo Impacto Ambiental (alíneas "a", "b", "c", "e", "f", "g", "h", “i”, “j” e "k", Inc. X, art. 3o, Lei n. 12.651/2012);

- $\quad$ Nascentes (Inc. XVII, art. 3oㅡㄴ, Lei n. 12651/2012);

- $\quad$ Olho d'água (Inc. XVIII, art. 3ํㅡ, Lei n. 12.651/2012);

- Leito regular (Inc. XIX, art. 3oㅡㄴ Lei n. 12.651/2012);

- $\quad$ Pousio (Inc. XXIV, art. 3ํㅡ, Lei 12.651/2012);

- $\quad$ Crédito de carbono (Inc. XXVII, art. 3oㅡ, Lei n. 12.651/2012);

- Áreas de Preservação Permanente (Incisos I, II, III, IV, art. 4º, artigos $7^{\circ}$, 8o e 9으, Lei n. 12651/2012);

- Áreas de Uso Restrito ("caput" e parágrafo $3^{\circ}$, art. 11, art. 13, art. 14, art. 15 , art. 16, art. 17, art. 18, art. 20, art 21, art. 22, art. 23, art. 24, Lei n. 12651/2012);

- $\quad$ Cadastro Ambiental Rural (art. 29, art. 30, Lei n. 12.651/2012);

- Programa de Apoio e Incentivo à Preservação e Recuperação do Meio Ambiente (art. 41, art. 42, art.44, art. 45, art. 46, art. 47, art. 48, art. 49 e art. 50, Lei n. 12.651/2012);

- Agricultura Familiar (art. 52, art. 53, art. 54, art. 55, art. 56, art. 57 e art. 58, Lie n. 12.651/2012);

- Áreas Consolidadas em Áreas de Preservação Permanente (art. 61-A, art. 61-B, art. 63, Lei n. 12.651/2012);

- Áreas Consolidadas em Áreas de Reserva Legal (art. 66, art. 67 art. 68, Lei n. 12.651/2012).

Por outro lado, haveria que se considerar, relativamente ao Decreto n. 8.375, de 11, de dezembro de 2014 (BRASIL, 2014), os seguintes aspectos:

- Alguns princípios e objetivos da Política Agrícola para Florestas Plantadas (artigos $3^{\circ}$ e $4^{\circ}$ ), tais como:

i. produção de bens e serviços florestais para o desenvolvimento social e econômico do país;

ii. melhorar a renda e a qualidade de vida no meio rural, notadamente em pequenas e médias propriedades rurais; e

iii. estimular a integração entre produtores rurais e agroindústrias que utilizem madeira como matéria-prima. 
- Alguns instrumentos e ações consoante previstos na Lei n. 8.171, de 17 de janeiro de 1991 como, por exemplo:

i. planejamento agrícola;

ii. pesquisa agrícola tecnológica;

iii. assistência técnica e extensão rural;

iv. proteção do meio ambiente, conservação e recuperação dos recursos naturais;

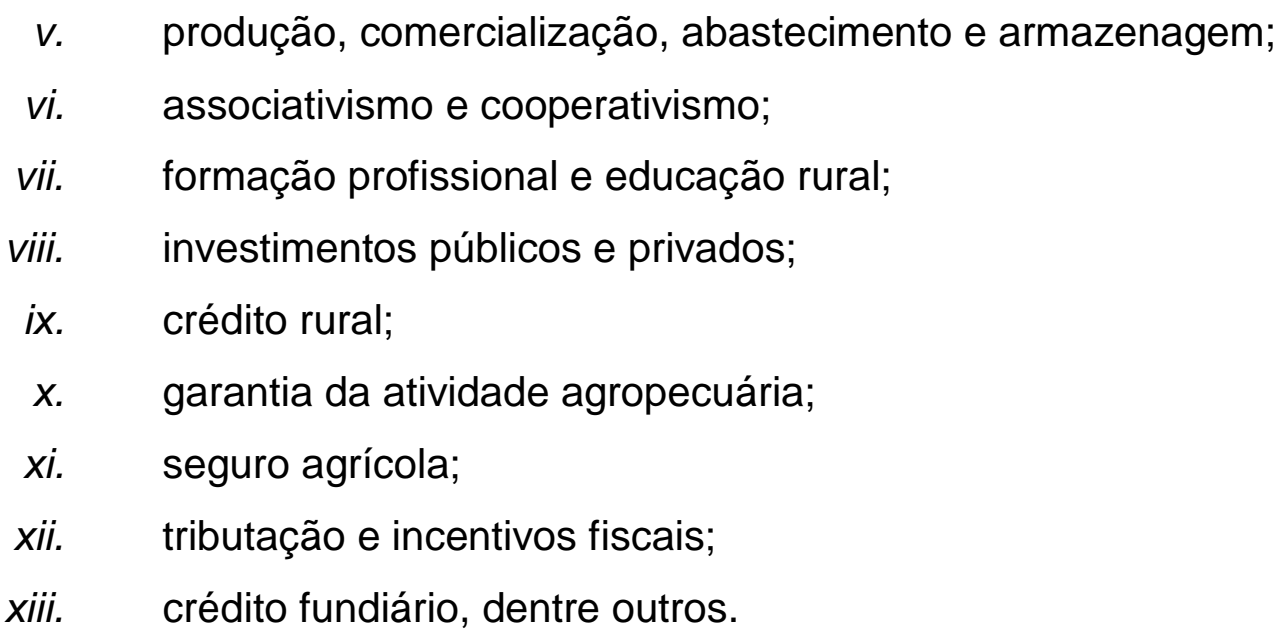

Haveria de se ressaltar, de qualquer maneira, que "a Política Agrícola para Florestas Plantadas não se aplica a Áreas de Preservação Permanente, de uso restrito e de Reserva Legal, de que tratam o art. 4º, o capítulo III e a seção I do capítulo IV da Lei no 12.651 , de 25 de maio de 2012".

A partir disto verifica-se, por fim, que a análise dos principais aspectos técnicos e legais visando a adequação ambiental das propriedades rurais do Jardim Chaparral deverá considerar, em última instância, e até o presente momento, a seguinte base legal (RIBAS, 2014):

i. Lei n. 12.651 , de 25 de maio de 2012. Dispõe sobre a proteção da vegetação nativa; altera as Leis nos 6.938, de 31 de agosto de 1981, 9.393, de 19 de dezembro de 1996, e 11.428, de 22 de dezembro de 2006; revoga as Leis nos 4.771, de 15 de setembro de 1965, e 7.754, de 14 de abril de 1989, e a Medida Provisória no 2.166-67, de 24 de agosto de 2001; e dá outras providências (Medida Provisória n. 571 , de 25 de maio de 2012. Altera a Lei no 12.651, de 25 de maio de 2012, que dispõe sobre a proteção da vegetação nativa; altera as Leis nos 6.938, de 31 de agosto de 1981, 9.393, de 19 de dezembro de 1996, e 11.428, de 22 de dezembro de 2006; revoga as Leis nos 4.771, de 15 de setembro de 1965, e 7.754, de 14 de abril de 1989, e a Medida Provisória no 2.166-67, de 24 de agosto de 2001; Lei n. 12.727, de 17 de outubro de 2012. Altera a Lei no 12.651, de 25 de maio de 2012, que dispõe sobre a proteção da vegetação nativa; altera as Leis nos 6.938 , de 31 de agosto de 1981, 9.393, de 19 de dezembro de 1996, e 11.428, de 22 de dezembro de 2006; e revoga as Leis nos 4.771, de 15 de setembro de 1965, e 7.754, de 14 de abril de 1989, a Medida Provisória no 2.166-67, de 24 de agosto de 2001, o item 22 do inciso 
II do art. 167 da Lei no 6.015 , de 31 de dezembro de 1973, e o $\S 20$ do art. 40 da Lei no 12.651 , de 25 de maio de 2012);

ii. Decreto n. 7830, de 17 de outubro de 2012. Dispõe sobre o Sistema de Cadastro Ambiental Rural, o Cadastro Ambiental Rural, estabelece normas de caráter geral aos Programas de Regularização Ambiental, de que trata a Lei no 12.651 , de 25 de maio de 2012, e dá outras providências;

iii. Decreto n. 8.235, de 05 de maio de 2014 - Estabelece normas gerais complementares aos Programas de Regularização Ambiental dos Estados e do Distrito Federal, de que trata o Decreto no 7.830, de 17 de outubro de 2012, institui o Programa Mais Ambiente Brasil, e dá outras providências;

iv. Instrução Normativa n. 2, de 5 de maio de 2014 - Dispõe sobre os procedimentos para a integração, execução e compatibilização do Sistema de Cadastro Ambiental Rural-SICAR e define os procedimentos gerais do Cadastro Ambiental Rural-CAR;

v. Resolução SMA n. 32 de 30 de abril de 2014 - Restauração ecológica no Estado de São Paulo;

vi. Decreto n. 8.375, de 11 de dezembro de 2014 - Define a Política Agrícola para Florestas Plantadas.

\section{CONCLUSÕES}

Os principais aspectos técnicos e legais de adequação ambiental de pequenas propriedades rurais e posses rurais familiares preconizados pela nova lei florestal são plenamente compatíveis tanto com a proteção, quanto, e principalmente, com o uso sustentável dos recursos florestais e se encontram correlacionados, a despeito do país não ser signatário do documento ambiental voluntário internacional, com algumas das principais diretivas da Carta de Nova York das Florestas.

A nova lei florestal brasileira pode ser considerada, consequentemente, como uma nova propositura de politica de proteção, conservação e restauração florestal, bem como de uso sustentável dos recursos florestais.

O conjunto normativo associado direta ou indiretamente à nova lei florestal possui, de outro modo, mecanismos (Pagamento por Serviços Ambientais, bem como Política Agrícola de Florestas Plantadas, por exemplo) que, quando aplicados às pequenas propriedades rurais ou posses rurais familiares, podem ser enquadrados nos novos programas multilaterais e bilaterais de remuneração dos países para a redução dos desmatamentos.

Diversos requisitos técnicos e legais para a adequação ambiental das pequenas propriedades rurais e posses rurais familiares previstos e/ou associados à nova lei florestal são, ademais, alinhados com mecanismos de emissão evitada de carbono, mitigação dos efeitos das mudanças climáticas, biodiversidade e áreas 
degradadas, dentre outros, previstos na Carta de Nova York e em documentos da ONU tais como as Metas de Aichi de Biodiversidade.

Todos estes elementos, por outro lado, encontram-se dispostos de maneira com que a nova lei florestal e os documentos ambientais nacionais e internacionais mencionados possam ser utilizados de forma integrada (governos, companhias e instituições da sociedade civil) no sentido de proporcionar a proteção e o uso sustentável dos recursos florestais pelas pequenas propriedades rurais e posses rurais familiares.

\section{REFERÊNCIAS BIBLIOGRÁFICAS}

BRASIL. Lei n. 8.171, de 17 de janeiro de 1991, dispõe sobre a política agrícola. Disponível em: <http://www.planalto.gov.br/ccivil_03/leis/l8171.htm>. Acesso em 06 jan. 2015.

Medida Provisória n. 2.166-67, de 24 de agosto de 2001. Altera os arts. 1o, 4o, 14, 16 e 44, e acresce dispositivos à Lei no 4.771, de 15 de setembro de 1965, que institui o Código Florestal, bem como altera o art. 10 da Lei no 9.393, de 19 de dezembro de 1996, que dispõe sobre o Imposto sobre a Propriedade Territorial Rural - ITR, e dá outras providências. Disponível em:

<http://www.planalto.gov.br/ccivil_03/mpv/2166-67.htm>. Acesso em 01 jul. 2014.

. Lei n. 11.326, de 24 de julho de 2006. Estabelece as diretrizes para a formulação da Política Nacional da Agricultura Familiar e Empreendimentos Familiares Rurais. Disponível em:

<http://www.planalto.gov.br/ccivil_03/_Ato2004-2006/2006/Lei/L11326.htm\#art3>. Acesso em 24 out. 2014.

. Lei n. 12.651, de 25 de maio de 2012. Dispõe sobre a proteção da vegetação nativa; altera as Leis nos 6.938, de 31 de agosto de 1981, 9.393, de 19 de dezembro de 1996, e 11.428, de 22 de dezembro de 2006; revoga as Leis nos 4.771, de 15 de setembro de 1965, e 7.754, de 14 de abril de 1989, e a Medida Provisória no 2.166-67, de 24 de agosto de 2001; e dá outras providências. Disponível em: <http://www.planalto.gov.br/ccivil_03/_ato2011-2014/2012/lei/l12651.htm>. Acesso em 24 out. 2014.

Decreto n. 8.375, de 11 de dezembro de 2014. Define a Política Agrícola para Florestas Plantadas. Disponível em: <https://www.planalto.gov.br/ccivil_03/_ato20112014/2014/decreto/d8375.htm>. Acesso: 06 jan. 2015.

EISENHARDT, Kathleen. M. Building theories from case study research. Academy of Management Review, New York, v. 14, n.4, p. 532-550, 1989.

GODOY, Arilda S. Estudo de caso qualitativo. In: GODOY, C. K.; BANDEIRA-DE-MELLO, R.; SILVA, A. B. Pesquisa qualitativa em estudos organizacionais. São Paulo: Saraiva, 2006. p. 115-146.

RIBAS, L. C. Relatório final. Diálogos da Sustentabilidade III. Faculdade de Ciências Agronômicas Universidade Estadual Paulista "Júlio de Mesquita Filho" (UNESP). Botucatu: FCA, 2014. 8 p. 
MMA. Decisão adotada pela Conferência das Partes da Convenção sobre Diversidade Biológica na sua Décima Reunião. Plano Estratégico de Biodiversidade 2011-2020. Disponível em: < http://www.mma.gov.br/estruturas/sbf2008_dcbio/_arquivos/metas_aichi_147.pdf>. Acesso em: 26 out. 2014.

ONU. New York Declaration on Forests. UN Climate Summit. Disponível em: <http://www.unredd.org/portals/15/documents/ForestsDeclarationText.pdf>. Acesso em: 26 out. 2014.

PORTAL BRASIL. Governo esclarece decisão sobre declaração para preservação de florestas. Blog do Planalto, Brasília. Disponível em:<http://www.brasil.gov.br/governo/2014/09/governo-esclarecedecisao-sobre-acordo-para-preservacao-de-florestas>. Acesso em: 26 out. 2014.

SILVA, Edna Lúcia; MENEZES, Estera Muszkat. Metodologia da pesquisa e elaboração de dissertação. 4 ed. rev. Florianópolis: UFSC, 2005. 138p. 